\title{
Unstable angina pectoris prior to ST elevation myocardial infarction in patients treated with primary percutaneous coronary intervention has no influence on prognosis
}

\author{
Krystyna Kluz a, , Jiri Parenica ${ }^{\mathrm{c}, \mathrm{d}}$, Lenka Kubkovaa, ${ }^{\mathrm{a}, \mathrm{c}, \mathrm{d}}$, Simona Littnerova ${ }^{\mathrm{e}}$, Josef Tomandl ${ }^{\mathrm{a}}$, Martin Poloczekc, Ondrej Tomanc, \\ Martin Tesakc, , Zdenka Cermakova ${ }^{g}$, Jana Gottwaldova ${ }^{g}$, Jan Manousek, , Monika Pavkova Goldbergovaa ${ }^{a}$, Jindrich Spinara,c,d, \\ Jiri Jarkovsky ${ }^{\mathrm{e}}$
}

Background. Pre-infarction unstable angina pectoris (UAP) can be considered ischemic preconditioning. The aim of this study was to compare short and long term outcomes in patients with or without pre-infarction UAP and ST elevation myocardial infarction (STEMI) treated with primary percutaneous coronary intervention ( $\mathrm{PCI}$ ).

Methods. 593 patients with STEMI (388 without and 205 with UAP) were evaluated. Levels of biomarkers (troponin $\mathrm{I}$, BNP, NT-ProBNP, neopterin, endoglin and pentraxin-3) at hospital admission and $24 \mathrm{~h}$ after STEMI onset were assessed. Echocardiography was undertaken on the fourth day after $\mathrm{Ml}$ and after 12 months. The median follow-up was 37 months.

Results. We found no significant differences in sex, age or risk factors for atherosclerosis between the UAP and non-UAP group. As the median time from the onset of chest pain to admission was significantly longer in the UAP group (228 min vs $258 \mathrm{~min} ; P=0.009$ ), we used a propensity score to obtain comparable matched groups for use in further analyses. The levels of NT-proBNP were significantly higher on admission and after 24 hours in the UAP group. Left ventricular functions according to invasive and echocardiographic parameters were entirely comparable at hospitalization and after 12 months. No differences were found in severity index of acute heart failure during hospitalization. The incidence of major acute coronary events during follow-up was comparable for the groups.

Conclusions. In patients with STEMI treated with primary PCI, pre-infarction UAP has no beneficial clinical effect during hospitalization or during long-term follow-up.

Key words: pre-infarction angina pectoris, STEMI, primary PCI, natriuretic peptides

Received: August 8, 2013; Accepted: January 14, 2014; Available online: January 23, 2014

http://dx.doi.org/10.5507/bp.2014.003

${ }^{a}$ Department of Internal Cardiology, Medical Faculty, Masaryk University, Brno, Czech Republic

${ }^{b}$ Hospital Podlesi a.s., Trinec

'Department of Cardiology, Faculty Hospital Brno

${ }^{d}$ Department of Cardiovascular Disease, International Clinical Research Center, St. Anne's University Hospital in Brno

eInstitute of Biostatistics and Analyses, Masaryk University, Brno

${ }^{f}$ Hospital Trebic, Trebic-Jejkov

${ }^{9}$ Department of Biochemistry, Faculty Hospital Brno

Corresponding author: e-mail:jarkovsky@iba.muni.cz

\section{INTRODUCTION}

Short periods of ischemia have been described in large number of experimental and clinical studies as protecting myocardial cells against following sustained ischemia of the myocardium ${ }^{1-3}$. Unstable angina pectoris (UAP) preceding myocardial infarction (pre-infarction or prodromal angina pectoris) represents intermittent ischemic periods which could be considered as ischemic preconditioning. It has been demonstrated that pre-infarction UAP resulted in decrease in mortality, acute heart failure, arrhythmias and infarction size $e^{4,5}$ patients with pre-infarction UAP had better short ${ }^{6}$ and long-term ${ }^{7}$ outcomes compared to $\mathrm{pa}^{-}$ tients with an abrupt onset of myocardial infarction. The main limitation of most studies is that they have been performed in patients with acute myocardial infarction treated with thrombolysis.
There is currently no general consensus on the causes of the protective effects of pre-infarction UAP although certain pathophysiological mechanisms have been described. The mechanism of ischemic preconditioning is based on activation of specific receptors on the cardiomyocyte cell membrane such as adenosine $\mathrm{A} 1\left(\mathrm{ref}^{8}\right)$, bradykinin B2 $\left(\right.$ ref. $\left.^{9}\right), \alpha 1 \mathrm{~A}$ - and $\beta 2$-adrenoreceptors ${ }^{10,11}$ and $\delta$-opioid receptors ${ }^{12}$. The signal transduction pathways downstream of the trigger are complex and involve multiple protein kinases, notably protein kinase $\mathrm{C}\left(\right.$ ref. $\left.^{13}\right)$, protein kinase $\mathrm{A}\left(\right.$ ref. $\left.^{14}\right)$, mitogen activated protein kinases ${ }^{15}$ and reperfusion injury salvage kinases (RISK pathway) $\left(\right.$ ref. $\left.{ }^{16}\right)$. A considerable role in the preconditioning is played by mitochondria. Mitochondrial $\mathrm{K}_{\mathrm{ATP}}$ channel modulation and prevention of mitochondrial pore transition protein (mPTP) opening reduces necrotic ${ }^{17-19}$ and apoptotic ${ }^{20}$ myocardial cell death. The final effects of 
preconditioning involve inhibition of $\mathrm{Ca}^{2+}$ overload, glucose uptake, structural holding, anti-inflammation and anti-apoptosis effects ${ }^{21}$. In addition, some studies have found that ischemic preconditioning preserves the anatomic microvasculature and functional vascular reactivity, as well limiting the impairment of coronary arteriolar dilation, arteriolar injury and endothelial dysfunction ${ }^{22}$. Other mechanisms involve the formation of thrombi that are less resistant to fibrinolysis ${ }^{4,23}$ or spontaneous recanalization of the infarction artery upon pre-infarction angina $^{24}$. Opening of thin-walled vascular channels that connect coronary arteries (coronary collaterals), caused by increased pressure resulting from subtotal occlusion has been also suggested as a cardioprotective effect of prodromal angina pectoris ${ }^{25,26}$. Although the data in general suggest a protective role of prodromal angina, the clinical benefits in the groups of patients with STEMI treated with primary percutaneous coronary intervention are still under discussion.

The aim of the analysis was to compare laboratory and invasive parameters, hospital outcomes and long term prognosis including occurrence of death, re-infarction, stroke, hospitalization due to acute heart failure (AHF) and left ventricle function in a group of consecutive patients with ST elevation myocardial infarction (STEMI) with or without pre-infarction UAP who were treated with primary percutaneous coronary intervention (PCI).

\section{METHODS}

\section{Study population}

From November 2005 to October 2008 a total of 593 patients with STEMI referred for primary PCI and admitted to the Coronary Care Unit (CCU) of the Internal Cardiology Department of the University Hospital Brno were included in the study. All patients were of Caucasian origin. Standard recommended therapy including ACE inhibitors, beta-blockers and statins administered as soon as possible after primary PCI. Exclusion criteria were: age over 80 years, known or newly diagnosed malignancy, inflammatory or connective tissue disease, previously known LV dysfunction and estimated life expectancy $<1$ year, refusal to sign informed consent or non-compliance, regional reasons (foreign citizens or distance from living place to the hospital of more than $100 \mathrm{~km}$ ). Informed written consent was obtained from all subjects before participation in the trial. The study protocol complied with the latest Declaration of Helsinki and was approved by the local Ethics Committee of the Faculty Hospital Brno and by the Ethics Committee of Masaryk University in Brno.

The diagnosis of STEMI was made on the basis of the presence of MI symptoms, relevant ECG changes (ST-segment elevation at the $\mathrm{J}$ point in two contiguous leads $\geq 0.1 \mathrm{mV}$ in all leads including V7-9, in leads V2-V3 $\geq 0.2 \mathrm{mV}$ in men $\geq 40$ years; $\geq 0.25 \mathrm{mV}$ in men $<40$ years, or $\geq 0.15 \mathrm{mV}$ in women or new LBBB) and elevation of troponin I as a marker of myocardial necrosis. Time from onset of chest pain to primary PCI was $<12 \mathrm{~h}$.
Pre-infarction UAP was defined as at least 1 occurrence of typical chest pain at rest within 7 days before the onset of MI. The time of the onset of myocardial infarction was defined as severe chest pain that did not subside spontaneously within $20 \mathrm{~min}$.

The diagnosis of acute heart failure was made according to the clinical signs on admission and/or during hospitalization (Killip I-IV).

The study sample was divided into 2 groups according to the presence of pre-infarction UAP: patients without unstable angina pectoris (non-UAP group, $n=388$ ) and patients with unstable angina preceding acute myocardial infarction (UAP group, $\mathrm{n}=205$ ).

\section{Laboratory methods}

Samples of venous blood for analyses of B type natriuretic peptide (BNP) and N-terminal pro B-type natriuretic peptide (NT-ProBNP) levels were drawn immediately upon hospital admission before primary PCI (sample 1). Blood samples were drawn again exactly at $24 \mathrm{~h}$ after the onset of chest pain (sample 2). Samples were centrifuged within $20 \mathrm{~min}$ in a refrigerated centrifuge, and the plasma and serum were stored at $-80^{\circ} \mathrm{C}$. Standard biochemical and haematological blood tests were done immediately on hospital admission before primary PCI and $24 \mathrm{~h}$ after the onset of chest pain (including Troponin-I ADSV, Abbott Laboratories, Abbott Park, USA). BNP was analyzed using the AxSYM BNP-Microparticle Enzyme Immunoassay (Abbott Laboratories, Abbott Park, USA). NT-ProBNP was analyzed using the Cobas E411 NT-proBNP Imunoassay Kit (Roche Diagnostics, Indianapolis). Neopterin concentrations were determined in duplicate by commercially available ELISA (IBL International $\mathrm{GmbH}$, Germany) following the manufacturer's instructions. Analytical sensitivity was $0.7 \mathrm{nmol} / \mathrm{L}$, and intra- and inter-assay $\mathrm{CV} \%$ were $<6 \%$ and $<9 \%$, respectively. Plasma levels of Pentraxin-3 were measured by commercially available sandwich ELISA (R\&D Systems Inc., MN, USA). The assay sensitivity was $25 \mathrm{pg} / \mathrm{mL}$, intra- and inter-assay precisions were $<4.4 \%$ and $<6.0 \%$, respectively. Plasma levels of endoglin were measured by commercially available sandwich ELISA (R\&D Systems Inc., MN, USA). The assay sensitivity was $7 \mathrm{pg} / \mathrm{mL}$, intra- and inter-assay precisions were $<3.2 \%$ and $<6.5 \%$, respectively.

\section{Echocardiography assessment}

Echocardiography assessment was carried out during the index admission ( $3^{\text {rd }}-5^{\text {th }}$ day after MI onset) and the second one during the follow-up. LV end-systolic volume (ESV), LV end-diastolic volume (EDV), and LV ejection fraction (EF) were mostly estimated using the bi-planar Simpson 's rule from apical two- and four-chamber views (90\% of values). The other values were determined using Teichholtz formula. EDV and ESV were indexed to body surface area. Echocardiography was assessed using Vivid 7 (GE Vingmed Ultrasound). 


\section{Invasive measurement}

Invasive intra-aortic systolic blood pressure (SBP) and diastolic blood pressure (DBP), LVEDP and $\mathrm{dP} / \mathrm{dt} / \mathrm{P}$ were measured before left ventricle angiography using a fluidfilled catheter ( $5 \mathrm{Fr}$ pigtail catheter) in the supine position of the patients before primary PCI. Ejection fraction was determined by left ventricle angiography. Heart rate was recorded using electrocardiographic monitoring. A diseased coronary vessel was defined as the presence of at least one $>50 \%$ reduction of intraluminal diameter on major coronary arteries (left main, left anterior descending, left circumflex, right coronary arteries) or their branches with diameter $\geq 2.0 \mathrm{~mm}$. Significant left main artery stenosis was coded as two-vessel disease.

\section{Follow-up}

Patients were prospectively monitored in the hospital cardiology outpatient department. Median follow-up was 37 months. The onset of death, myocardial re-infarction, stroke or hospitalization due to acute heart failure was included in the evaluation. The median follow-up to the last echocardiography and laboratory samples including natriuretic peptides was 12.2 months.

\section{Statistical analysis}

Standard descriptive statistics were applied; median and $5^{\text {th }}-95^{\text {th }}$ percentile range were used for continuous variables and absolute and relative frequencies for categorical variables. The statistical significance of differences between groups of patients was evaluated by Mann- Whitney $\mathrm{U}$ test for continuous variables and Fisher exact test for categorical variables. The statistical significance of differences among groups of patients was computed using the Kruskal-Wallis test, followed by post-hoc comparison of mean ranks. The survival of patients was described using the Kaplan-Meier survival curve and the comparison of groups of patients was computed using the log-rank test. Considering that the groups were not entirely comparable, the propensity score method was used to create two comparable matched groups according to the baseline characteristics.

\section{RESULTS}

A total of 593 patients were enrolled in the analysis and 205 of them had pre-infarction UAP. Baseline characteristics are shown in Table 1. No significant differences in baseline characteristics were found for the two groups excluding the median time from the onset of chest pain to admission to the CCU, which was statistically significantly longer in the UAP group. As 30 min of the longer delay in the UAP group could play a clinically significant role, which could diminish positive effect of previous UAP,

Table 1. Baseline characteristics according to the presence of prodromal unstable angina pectoris in all patients and in matched groups using propensity score.

\begin{tabular}{|c|c|c|c|c|c|c|}
\hline Patient & $\begin{array}{l}\text { Non-UAP } \\
\text { group* } \\
(n=388)\end{array}$ & $\begin{array}{l}\text { UAP } \\
\text { group* } \\
(n=205)\end{array}$ & $P^{* *}$ & $\begin{array}{c}\text { Non-UAP } \\
\text { matched group* } \\
(n=200)\end{array}$ & $\begin{array}{l}\text { UAP matched } \\
\text { group* } \\
\qquad(n=200)\end{array}$ & $P^{* *}$ \\
\hline Age & $62.8(45.2 ; 79.0)$ & $62.3(44.3 ; 77.9)$ & 0.588 & $63.7(45.7 ; 79.7)$ & $62.1(44.3 ; 78.1)$ & 0.239 \\
\hline Men & $76.0 \%$ & $72.7 \%$ & 0.371 & $72.5 \%$ & $72.5 \%$ & 1.000 \\
\hline BMI $\left(\mathrm{kg} / \mathrm{m}^{2}\right)$ & $27.4(22.4 ; 34.5)$ & $28.1(22.8 ; 35.2)$ & 0.051 & $27.4(22.4 ; 34.3)$ & $28.1(22.7 ; 35.3)$ & 0.091 \\
\hline Aortic systolic pressure $(\mathrm{mmHg})$ & $133(93 ; 184)$ & $135(95 ; 178)$ & 0.206 & $140(93 ; 190)$ & $140(92 ; 188)$ & 0.987 \\
\hline Aortic diastolic pressure (mmHg) & $73(51 ; 96)$ & $76(53 ; 101)$ & 0.085 & $80(55 ; 102)$ & $80(58 ; 105)$ & 0.723 \\
\hline Heart rate $\left(\mathrm{min}^{-1}\right)$ & $73(50 ; 106)$ & $74(54 ; 109)$ & 0.926 & $74(50 ; 111)$ & $74(54 ; 109)$ & 0.942 \\
\hline Time door-to-balloon (min) & $64(40 ; 100)$ & $63(40 ; 98)$ & 0.369 & $64(40 ; 105)$ & $63(40 ; 99)$ & 0.212 \\
\hline Delay & $228(124 ; 640)$ & $258(120 ; 675)$ & 0.009 & $250(130 ; 658)$ & $255(120 ; 656)$ & 0.661 \\
\hline Smoking & $55.9 \%$ & $53.2 \%$ & 0.521 & $47.0 \%$ & $47.0 \%$ & 1.000 \\
\hline Diabetes mellitus & $25.3 \%$ & $30.2 \%$ & 0.193 & $22.5 \%$ & $30.5 \%$ & 0.069 \\
\hline Hypertension & $55.2 \%$ & $58.5 \%$ & 0.430 & $61.5 \%$ & $58.0 \%$ & 0.475 \\
\hline Hyperlipoproteinemia & $83.0 \%$ & $82.9 \%$ & 0.985 & $84.5 \%$ & $82.5 \%$ & 0.590 \\
\hline Previous ACEI/AT2 & $32.2 \%$ & $28.8 \%$ & 0.390 & $36.0 \%$ & $28.5 \%$ & 0.108 \\
\hline Previous Beta blockers & $25.3 \%$ & $29.3 \%$ & 0.293 & $27.5 \%$ & $29.0 \%$ & 0.739 \\
\hline
\end{tabular}

*Continuous parameters are described using median and 5-95 th percentile; categorical parameters are described by frequency and percentage of categories, **Statistical significance evaluated by Mann-Whitney U test for continuous variables and Fisher exact test for categorical variables; Delay - time from onset of chest pain to primary PCI (the first balloon dilatation); AT2 - antagonist for type 2 of receptor for angiotensin II; ACEI - angiotensin-converting enzyme inhibitors. 
we used a propensity score to obtain comparable groups. After matching the groups, the delay to admission to the CCU was comparable in both groups (Table 1).

The laboratory findings for the matched groups are shown in Table 2. The difference in the laboratory findings in the matched groups was significantly higher levels of NT-proBNP in UAP-group at admission as well as over $24 \mathrm{~h}$ after MI onset. Prognostic biomarkers neopterin and endoglin were comparable within both groups; pentraxin-3 level in UAP group was significantly lower after $24 \mathrm{~h}$.

Invasive and echocardiography parameters are presented in Table 3 and we found no statistically significant differences in either invasive or echocardiography parameters between the matched groups.

The hospitalization course was comparable in both matched groups. There was no statistical difference in the occurrence of acute heart failure (nonUAP vs UAP group $28.6 \%$ vs $25.9 \%$; $P=\mathrm{NS}$ ) or its severity.

We found no differences in EF or left ventricle volumes during follow-up (Table 3).

The median follow-up of patients was 37 months. No differences in the occurrence of the separate endpoints or composite endpoints of death, hospitalisation due to AHF, re-infarction and stroke were detected during the follow between the matched groups with or without preinfarction UAP. The long-term survival and occurrence of all monitored cardiovascular events are shown in Fig. 1.

\section{DISCUSSION}

The results of this prospective study on patients with STEMI treated by primary PCI showed no differences in

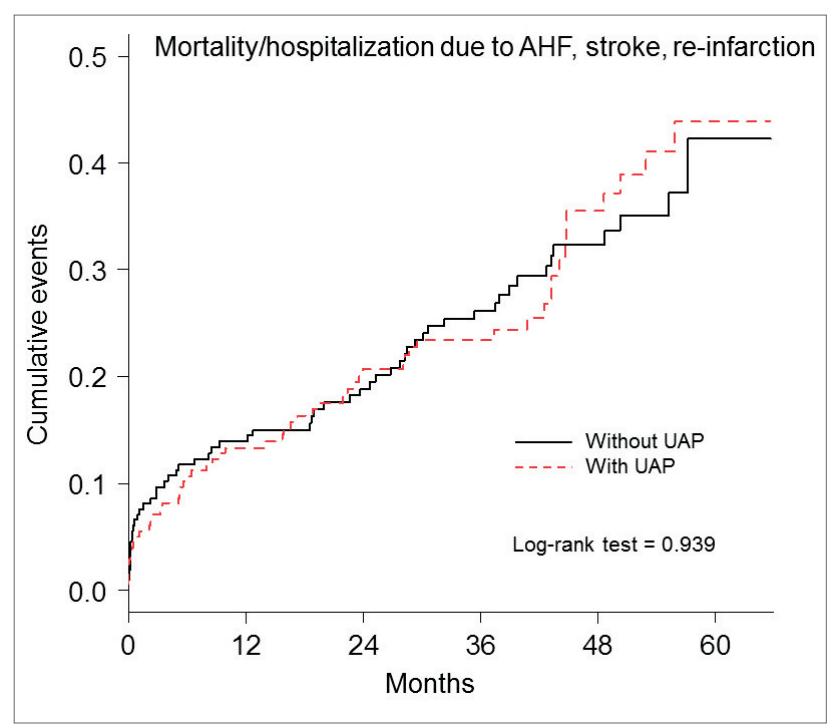

Fig. 1. The long-term survival and occurrence of cardiovascular events. Kaplan-Meier's curve of event-free survival (without death, re-infarction, hospitalization due to AHF and stroke) according to the presence of pre-infarction UAP (matched groups).

acute heart failure rate, invasive or echocardiographic parameters of left ventricle dysfunction or long term prognosis for patients with pre-infarction UAP and those without. Due to clinically significantly longer time from the onset of chest pain to primary PCI in the UAP group which could mask the protective effect of pre-infarction instability, we adopted a propensity score method to obtain two well matched groups with and without pre-infarction UAP.

Table 2. Laboratory results and prognostic biomarkers according to the prodromal unstable angina pectoris in matched groups using propensity score.

\begin{tabular}{lccc}
\hline \multirow{2}{*}{ Marker } & Non UAP matched group* & UAP matched group* & $P^{* *}$ \\
& $\mathrm{n}=200$ & $85(61 ; 1260)$ & 0.195 \\
Creatinine $(\mu \mathrm{mol} / \mathrm{L})$ & $88(60 ; 138)$ & $138(134 ; 143)$ & 0.126 \\
Sodium $(\mathrm{mmol} / \mathrm{L})$ & $139(133 ; 144)$ & $4.0(3.2 ; 4.9)$ & 0.675 \\
Potassium $(\mathrm{mmol} / \mathrm{L})$ & $4.0(3.2 ; 5.0)$ & $7.9(5.5 ; 19.4)$ & 0.330 \\
Glucose $(\mathrm{mmol} / \mathrm{L})$ & $8.0(5.6 ; 15.7)$ & $44.0(2.3 ; 192.8)$ & 0.091 \\
Troponin $\mathrm{I}(\mathrm{ng} / \mathrm{mL})$ & $48.8(5.0 ; 187.9)$ & $5.4(3.4 ; 7.2)$ & 0.233 \\
Cholesterol $(\mathrm{mmol} / \mathrm{L})$ & $5.4(3.6 ; 7.9)$ & $1.5(0.6 ; 3.8)$ & 0.754 \\
Triglycerides $(\mathrm{mmol} / \mathrm{L})$ & $1.57(0.6 ; 5.9)$ & $144(122 ; 165)$ & 0.688 \\
Hemoglobin $(\mathrm{g} / \mathrm{L})$ & $144(119 ; 165)$ & $78(15 ; 572)$ & 0.155 \\
BNP at admission $(\mathrm{pg} / \mathrm{mL}) / 1$ & $66(15 ; 473)$ & $280(71 ; 1093)$ & 0.984 \\
BNP after $24 \mathrm{~h}(\mathrm{pg} / \mathrm{mL})$ & $272(61 ; 1139)$ & $440(43 ; 5418)$ & $<\mathbf{0 . 0 0 1}$ \\
NT-proBNP at admission $(\mathrm{pg} / \mathrm{mL})$ & $202(28 ; 4605)$ & $2232(582 ; 11785)$ & $\mathbf{0 . 0 3 4}$ \\
NT-proBNP after $24 \mathrm{~h}(\mathrm{pg} / \mathrm{mL})$ & $1872(288 ; 11800)$ & $7.9(4.7 ; 16.6)$ & 0.976 \\
Neopterin - after $24 \mathrm{~h}$ & $7.9(4.4 ; 17.9)$ & $3.69(2.77 ; 4.99)$ & 0.784 \\
Endoglin at admission & $3.65(2.72 ; 5.32)$ & $3.70(2.70 ; 4.68)$ & 0.741 \\
Endoglin - after $24 \mathrm{~h}$ & $3.70(2.68 ; 5.09)$ & $0.88(0.25 ; 5.35)$ & 0.147 \\
Pentraxin-3 at admission & $1.08(0.34 ; 4.57)$ & $1.90(0.47 ; 17.47)$ & $\mathbf{0 . 0 4 1}$ \\
Pentraxin-3 - after $24 \mathrm{~h}$ & $2.65(0.54 ; 37.47)$ & & \\
\hline
\end{tabular}

*Continuous parameters are described using median and 5-95th percentile; **Statistical significance evaluated by Mann-Whitney U test for continuous variables; BNP - B-type natriuretic peptide 
Table 3. Invasive and echocardiography parameters in patients according to previous UAP.

\begin{tabular}{|c|c|c|c|}
\hline Parameter & $\begin{array}{l}\text { Non-UAP matched group* } \\
\qquad \mathrm{n}=200\end{array}$ & $\begin{array}{l}\text { UAP matched group* } \\
\qquad \mathrm{n}=200\end{array}$ & $P^{* *}$ \\
\hline TIMI flow - initial & & & 0.477 \\
\hline 0 & $64.0 \%$ & $56.5 \%$ & \\
\hline 1 & $7.0 \%$ & $9.5 \%$ & \\
\hline 2 & $15.0 \%$ & $17.5 \%$ & \\
\hline 3 & $14.0 \%$ & $16.5 \%$ & \\
\hline IRA - nonLAD & $48.0 \%$ & $45.5 \%$ & 0.616 \\
\hline IRA - LAD+LM & $44.0 \%$ & $45.0 \%$ & 0.841 \\
\hline Collaterals of IRA & $27.0 \%$ & $28.5 \%$ & 0.738 \\
\hline EF (angiography) (\%) & $50.0(30.0 ; 68.0)$ & $50.0(26.0 ; 68.0)$ & 0.450 \\
\hline LVEDP (mmHg) & $25.0(13.0 ; 39.0)$ & $25.5(11.0 ; 38.0)$ & 0.639 \\
\hline EF baseline (\%) & $53.0(30.0 ; 67.0)$ & $52.0(32.0 ; 67.0)$ & 0.941 \\
\hline Baseline EDV/BSA $\left(\mathrm{mL} / \mathrm{m}^{2}\right)$ & $60.5(34.9 ; 87.1)$ & $61.0(33.6 ; 99.9)$ & 0.459 \\
\hline Baseline ESV/BSA $\left(\mathrm{mL} / \mathrm{m}^{2}\right)$ & $27.4(12.7 ; 49.7)$ & $29.2(14.0 ; 51.0)$ & 0.570 \\
\hline Last EF (\%) & $55.0(32.0 ; 68.0)$ & $55.0(31.0 ; 69.0)$ & 0.983 \\
\hline Last EDV/BSA $\left(\mathrm{mL} / \mathrm{m}^{2}\right)$ & $59.6(35.5 ; 94.8)$ & $62.7(37.5 ; 110.1)$ & 0.277 \\
\hline Last ESV/BSA $\left(\mathrm{mL} / \mathrm{m}^{2}\right)$ & $26.8(13.3 ; 55.4)$ & $26.7(14.3 ; 63.7)$ & 0.469 \\
\hline
\end{tabular}

*Continuous parameters are described using median and 5-95 th percentile; categorical parameters are described by frequency and percentage of categories, **Statistical significance evaluated by Mann-Whitney U test for continuous variables and Fisher exact test for categorical variables; IRA - infarct related artery, LAD - left anterior descending coronary artery, RD - ramus diagonalis, RCX - ramus circumflexus, RCA - right coronary artery, LM - left main, EF - ejection fraction, LVEDP - left ventricular end-diastolic pressure, EDV - end-diastolic volume of left ventricle, ESV - end-systolic volume of left ventricle, BSA - body surface area.

As in the unmatched data, we found no protective effect of pre-infarction UAP in the matched groups.

Based on evaluation of prognostic biomarker analysis within the UAP group there was only a non-significant trend to lower levels of troponin I as a marker of myocardial necrosis, slightly higher levels of NT-proBNP on admission and after $24 \mathrm{~h}$ (but not for BNP) and slightly lower level of pentraxin-3 after $24 \mathrm{~h}$ as a marker of inflammation. Levels of other new prognostic biomarkers after ACS - neopterin and endoglin were comparable for both groups.

Our data do not support the hypothesis that pre-infarction angina has a protective role.

In comparison with previous studies, the influence of pre-infarction angina was assessed for the first time in a large population of patients with STEMI treated with primary PCI followed-up prospectively on a long-term basis. Most of the previous clinical studies on pre-infarction UAP were performed in the time of thrombolytic treatment of myocardial infarction ${ }^{47,23,27,28}$. Ishihara et al. reported that prodromal angina $24 \mathrm{~h}$ before infarction was associated with a more frequent patent infarct-related coronary artery before reperfusion therapy (34\% vs. $22 \%$, $P=0.03$ ) and with reperfusion after thrombolytic therapy ( $80 \%$ vs. $60 \%, P=0.002$ ) $\left(\right.$ ref. $^{29}$ ). This could be explained by faster dissolution of the thrombus in the presence of pre-infarction angina. Przyklenk et al. suggested in their experimental study that a short period of ischemia enhances the thrombolysis by induction of recombinant tissue plasminogen ${ }^{30}$. In patients treated by primary PCI, prodromal UAP was not associated with any significant differences between groups with/without pre-infarction UAP with respect to the patency of the infarct-related artery (TIMI-3 flow) either before the procedure $(2.2 \%$ vs. $0 \%, P=1.0)$ or after it $(84.8 \%$ vs. $84.4 \%, P=1.0)\left(\right.$ ref..$\left.^{31}\right)$.

The effect of pre-infarction UAPs in patients with acute myocardial infarction treated with primary PCI was evaluated only for hospitalization outcomes or a 30-day follow up so far ${ }^{32,33}$; our results provide information about long-term follow-up for the first time.

Evidence for the prognostic significance of pre-infarction UAP in the era of aggressive STEMI PCI treatment ${ }^{34}$ is controversial. Although some studies have described better outcome in patients with pre-infarction UAP (ref. ${ }^{35}$ ), in other studies no differences in the levels of cardiac enzymes - CKMB or troponin I (ref. ${ }^{31,36}$ ) or infarct size measured by $99 \mathrm{mTc}$ sestamibi ${ }^{37}$ were found. In our study, there were no differences in the infarction size measured by the levels of troponin I in the groups with and without preinfarction angina (44 ng/mL vs. $48.8 \mathrm{ng} /$ $\mathrm{mL}, P=\mathrm{NS})$.

Recently Lorgis et al. suggested a beneficial effect of pre-infarction angina on short-term outcomes, especially ventricular arrhythmias and infarct size in NSTEMI pa- 
tients $^{38}$. This beneficial effect is less apparent in patients with CV risk factors (hypertension, obesity), or under chronic use of CV drugs such as aspirin or nitrates. This implies that prior treatment may also modify the disease process and clinical presentation. Nitroglycerin has a cardioprotective effect against ischemia through a protein kinase C-dependent pathway which is also one of the mediators in the preconditioning process ${ }^{39,40}$.

We found significantly higher levels of NT-proBNP, especially on admission, in patients with pre-infarction UAP. It is known that ischemia triggers the release of natriuretic peptides $^{41}$. As we found no differences in other parameters associated with acute heart failure or left ventricular dysfunction (ejection fraction, left ventricular end-diastolic pressure, end-diastolic and end-systolic volume - Table 3), we assume that the higher levels of NT-proBNP in patients with pre-infarction UAP were caused predominantly by previous ischemic insult.

Neopterin is a marker of macrophage activation with a putative physiological role in enhancing macrophage cytotoxicity. It was demonstrated that elevated levels are an independent prognostic markers of death, recurrent acute coronary syndrome and heart failure hospitalization after ACS (ref. ${ }^{42,43}$ ). We found no influence of pre-infarction UAP on neopterin levels which corresponds with similar long-term prognosis of both groups irrespective of prodromal angina.

Endoglin is a proliferation-associated and hypoxia-inducible glycoprotein expressed in endothelial cells. The level of endoglin decreases after MI and early endoglin decrease is an independent predictor of short term mortality ${ }^{44}$. We found no influence of pre-infarction UAP on levels of endoglin.

Pentraxin-3 is a long pentraxin, a marker of vascular inflammation ${ }^{45}$ such as the short pentraxin C-reactive protein. Pentraxin-3 has been shown to be an independent prognostic marker of 3-month mortality in patients with STEMI (ref. ${ }^{46}$ ). We found no difference in level of pentraxin-3 on admission but only slightly higher level of pentraxin-3 in patients without UAP after matching. This result could suggest that prodromal angina may result in milder inflammation reaction in patients with pre-infarction UAP but without influence on clinical outcomes.

\section{Limitations}

Although the number of patients here was sufficient for evaluating the clinical significance of prodromal UAP in an unselected cohort, assessment of the effect of UAP was not possible in various subgroups of patients, for example according to duration of prodromal chest pain, repeated chest pain, age or co-morbidities such as diabetes mellitus. For this reason, a larger sample of patients could provide more information. Another limitation of this study is that the diagnosis of ischemia was based on patient reported symptoms only.

\section{CONCLUSION}

In patients with ST elevation MI treated with primary PCI, pre-infarction UAP does not have a beneficial effect concerning acute heart failure occurrence, left ventricular function and the incidence of cardiovascular end-points during the long-term follow-up. There is a minimal effect of the pre-infarction UAP on the level of novel prognostic biomarkers such as neopterin, endoglin or pentraxin-3. Prodromal angina increases levels of NT-proBNP at admission and $24 \mathrm{~h}$ after; the mechanism is probably previous ischemic insult. There is alarming high percentage of patients with symptoms of prodromal unstable angina pectoris who are admitted into the hospital at the stage of myocardial infarction with ST elevation.

\section{ACKNOWLEDGEMENTS}

This work was supported by the Project of Conceptual Development of Research Organization (Department of Health) 65269705, SUp 17/13 (University Hospital Brno), Grant MUNI/A/0914/2012 and by the European Regional Development Fund - Project FNUSA-ICRC (No. CZ.1.05/1.1.00/02.0123).

We thank the study investigators for their contribution to the study. Faculty Hospital Brno, Czech Republic: Ludmila Dostalova, Katarina Marcinechova, Hana Jakubickova, Ivana Klabenesova, Ludmila Malaskova.

Author contributions: KK, JP, LK: manuscript writing; JP, JS, JT, MT, MPG: data interpretation; MP, OT, ZC, JG, JM: data collection; JJ, SL: statistical analysis, figures; KK, JP, LK, SL, JT, MP, OT, MT, ZC, JG, JM, MPG, JS, $\mathrm{JJ}$ : final approval.

Conflict of interest statement: None declared.

\section{REFERENCE}

1. Murry CE, Jennings RB, Reimer KA. Preconditioning with ischemia: a delay of lethal cell injury in ischemic myocardium. Circulation 1986;74(5):1124-36.

2. Rajesh KG, Sasaguri S, Zhitian Z, Suzuki R, Asakai R, Maeda H. Second Windows of ischemic preconditioning regulates mitochondrial permeability transition pore by enhancing $\mathrm{Bcl}-2$ expression. Cardiovasc Res 2003;59(2):297-307.

3. Wang L, Cherednichenko G, Hernandez L, Halow J, Camacho SA Figueredo V, Schaefer S. Preconditioning limits mitochondrial $\mathrm{Ca}(2+)$ during ischemia in rat hearts: role of K(ATP) channels. Am J Physiol Heart Circ Physiol 2001;280(5):H2321-8.

4. Andreotti F, Pasceri V, Hackett DR, Davies GJ, Haider AW, Maseri A. Preinfarction angina as a predictor of more rapid coronary thrombolysis in patients with acute myocardial infarction. $N$ Engl J Med 1996;334(1):7-12.

5. Ottani F, Galvani M, Ferrini D, Sorbello F, Limonetti P, Pantoli D, Rusticali F. Prodromal angina limits infarct size. A role for ischemic preconditioning. Circulation 1995;91(2):291-7.

6. Shiraki H, Yoshikawa T, Anzai T, Negishi K, Takahashi T, Asakura Y, Akaishi M, Mitamura H, Ogawa S. Association between preinfarction angina and a lower risk of right ventricular infarction. N Engl J Med 1998;338(14):941-7.

7. Ishihara M, Sato H, Tateishi H, Kawagoe T, Shimatani Y, Kurisu S, Sakai $\mathrm{K}$, Ueda K. Implications of prodromal angina pectoris in anterior 
wall acute myocardial infarction: acute angiographic findings and long-term prognosis. J Am Coll Cardiol 1997;30(4):970-5.

8. Liu GS, Thornton J, Van Winkle DM, Stanley AW, Olsson RA, Downey $J M$. Protection against infarction afforded by preconditioning is mediated by $\mathrm{A} 1$ adenosine receptors in rabbit heart. Circulation 1991;84(1):350-6.

9. Kositprapa C, Ockaili RA, Kukreja RC. Bradykinin B2 receptor is involved in the late phase of preconditioning in rabbit heart. J Mo Cell Cardiol 2001;33(7):1355-62.

10. Rorabaugh BR, Ross SA, Gaivin RJ, Papay RS, McCune DF, Simpson PC, Perez DM. $a_{1 A}$ - but not $a_{1 B}$-adrenergic receptors precondition the ischemic heart by a staurosporine-sensitive, chelerythrine-insensitive mechanism. Cardiovasc Res 2005;65(2):436-445. doi: 10.1016/j. cardiores.2004.10.009.

11. Tong H, Bernstein D, Murphy E, Steenbergen C. The role of beta-adrenergic receptor signaling in cardioprotection. FASEB 2005;19(8):983-5.

12. Schultz JE, Rose E, Yao Z, Gross GJ. Evidence for involvement of opioid receptors in ischemic preconditioning in rat hearts. Am J Physiol 1995;268(5 Pt 2):H2157-61.

13. Ytrehus K, Liu Y, Downey JM. Preconditioning protects ischemic rabbit heart by protein kinase C activation. Am J Physiol 1994;266(3 Pt 2):H1145-52.

14. Lochner A, Genade S, Tromp E, Podzuweit T, Moolman JA. Ischemic preconditioning and the beta-adrenergic signal transduction pathway. Circulation 1999;100(9):958-66.

15. Sanada S, Kitakaze M, Papst PJ, Hatanaka K, Asanuma H, Aki T, Shinozaki Y, Ogita H, Node K, Takashima S, Asakura M, Yamada J, Fukushima T, Ogai A, Kuzuya T, Mori H, Terada N, Yoshida K, Hori M. Role of phasic dynamism of p38 mitogen-activated protein kinase activation in ischemic preconditioning of the canine heart. Circ Res 2001;88(2):175-80.

16. Hausenloy DJ, Tsang A, Yellon DM. The reperfusion injury salvage kinase pathway: a common target for both ischemic preconditioning and postconditioning. Trends Cardiovasc Med 2005;15(2):69-75 Review.

17. Miura T, Tanno M, Sato T. Mitochondrial kinase signalling pathways in myocardial protection from ischaemia/reperfusion-induced necrosis. Cardiovasc Res 2010;88(1):7-15. Review.

18. Costa AD, Garlid KD. Intramitochondrial signaling: interactions among mitoKATP, PKCepsilon, ROS, and MPT. Am J Physiol Heart Circ Physiol 2008;295(2):H874-82. doi: 10.1152/ajpheart.01189.2007

19. Halestrap AP, Clarke SJ, Javadov SA. Mitochondrial permeability transitiv pore opening during myocardial reperfusion- a target for cardioprotection. Cardiovasc Res 2004;61(3):372-85. Review.

20. Bishopric NH, Andreka P, Slepak T, Webster KA. Molecular mechanisms of apoptosis in the cardiac myocyte. Curr Opin Pharmaco 2001;1(2):141-50. Review.

21. Sanada S, Komuro I, Kitakaze M. Pathophysiology of myocardial reperfusion injury: preconditioning, postconditioning, and translational aspects of protective measures. Am J Physiol Heart Circ Physiol 2011;301(5):H1723-41. doi: 10.1152/ajpheart.00553.2011

22. Richard V, Kaeffer N, Tron C, Thuillez C. Ischemic preconditioning proteus against coronary endothelial dysfunction induced by ischemia and reperfusion. Circulation 1994;89(3):1254-61.

23. Bahr RD, Leino EV, Christenson RH. Prodromal unstable angina in acute myocardial infarction: prognostic value of short- and long-term outcome and predictor of infarct size. Am Heart 2000;140(1):126-33.

24. Lee CW, Hong MK, Lee JH, Yang HS, Kim JJ, Park SW, Park SJ. Determinants and prognostic significance of spontaneous coronary recanalization in acute myocardial infarction. Am J Cardiol 2001;87(8):951-4; A3.

25. Ishihara M, Inoue I, Kawagoe T, Shimatani Y, Kurisu S, Hata T, Mitsuba $\mathrm{N}$, Kisaka T, Nakama H, Kijima Y. Comparison of the cardioprotective effect of prodromal angina pectoris and collateral circulation in patients with a first anterior wall acute myocardial infarction. Am J Cardiol 2005;95(5):622-5.

26. Billinger M, Fleisch M, Eberli FR, Garachemani A, Meier B, Seiler C. Is the development of myocardial tolerance to repeated ischemia in humans due to preconditioning or to collateral recruitment? J Am Coll Cardiol 1999;33(4):1027-35.

27. Tomoda H, Aoki N. Comparison of protective effects of preinfarction angina pectoris in acute myocardial infarction treated by throm- bolysis versus by primary coronary angioplasty with stenting. Am J Cardiol 1999;84(6):621-5.

28. Papadopoulos CE, Zioutas DG, Giannakoulas GA, Matsiras $S$, Karamitsos TD, Karvounis HI, Geleris P, Stiliadis I. Beneficial effect of ischemic preconditioning on post-infarction left ventricular remodeling and global left ventricular function. Cardiovasc Revasc Med 2011;12(5):286-91. doi: 10.1016/j.carrev.2010.11.005

29. Ishihara M, Sato H, Tateishi H, Kawagoe T, Shimatani Y, Kurisu S, Sakai $\mathrm{K}$, Ueda K. Implications of prodromal angina pectoris in anterior wall acute myocardial infarction: acute angiographic findings and long-term prognosis. J Am Coll Cardiol 1997;30(4):970-5.

30. Przyklenk K, Whittaker P. Brief antecedent ischemia enhances recombinant tissue plasminogen activator-induced coronary thrombolysis by adenosine-mediated mechanism. Circulation 2000;102(1):88-95.

31. Iglesias-Garriz I, Fernández-Vazquez F, Perez A, Jimenez-Bonilla J, Garrote C, Uriarte P, Delafuente C. Preinfarction angina limits myocardial infarction size in nondiabetic patients treated with primary coronary angioplasty. Chest 2005;127(4):1116-21.

32. Tomoda H, Aoki N. Coronary blood flow in evolving myocardial infarction preceded by preinfarction angina: a critical reevaluation of preconditioning effects in clinical cases. Angiology 2004;55(1):9-15.

33. Zahn R, Schiele R, Schneider S, Gitt AK, Seidl K, Bossaller C, Schuler G, Gottwik M, Altmann E, RosahI W, Senges J. Effect of preinfarction angina pectoris on outcome in patients with acute myocardial infarction treated with primary angioplasty (results from the Myocardial Infarction Registry). Am J Cardiol 2001;87(1):1-6.

34. Kala P, Miklik R. Pharmaco-mechanic antithrombotic strategies to reperfusion of the infarct-related artery in patients with ST-elevation acute myocardial infarctions. J Cardiovasc Transl Res 2013;6(3):37887. doi:10.1007/s12265-013-9448-1

35. Ottani F, Galli M, Zerboni S, Galvani M. Prodromal angina limits infarct size in the setting of acute anterior myocardial infarction treated with primary percutaneous intervention. J Am Coll Cardiol 2005;45(9):1545-7.

36. Tomoda H, Aoki N. Comparison of protective effects of preinfarction angina pectoris in acute myocardial infarction treated by thrombolysis versus by primary coronary angioplasty with stenting. Am J Cardiol 1999;84(6):621-5.

37. De Luca G, Parodi G, Sciagrà R, Bellandi B, Comito V, Vergara R, Migliorini A, Valenti R, Antoniucci D. Preinfarction angina does not affect infarct size in STEMI patients undergoing primary angioplasty. Atherosclerosis 2013;226(1):153-6. doi: 10.1016/j.atherosclerosis.2012.09.008

38. Lorgis L, Gudjoncik A, Richard C, Mock L, Buffet P, Brunel P, JaninManificat L, Beer JC, Brunet D, Touzery C, Rochette L, Cottin Y, Zeller M. Pre-infarction angina and outcomes in non-ST-segment elevation myocardial infarction: data from the RICO survey. PLoS One 2012;7(12):e48513. doi: 10.1371/journal.pone.0048513

39. Banerjee S, Tang XL, Qiu Y, Takano H, Manchikalapudi S, Dawn B, Shirk G, Bolli R. Nitroglycerin induces late preconditioning against myocardial stunning via a PKC-dependent pathway. Am J Physiol 1999;277(6 Pt 2):H2488-94.

40. Leesar MA, Stoddard MF, Dawn B, Jasti VG, Masden R, Bolli R. Delayed preconditioning-mimetic action of nitroglycerin in patients undergoing coronary angioplasty. Circulation 2001;103(24):2935-41.

41. Hama N, Itoh H, Shirakami G, Nakagawa O, Suga S, Ogawa Y, Masuda I, Nakanishi K, Yoshimasa T, Hashimoto Y, Yamaguchi M, Hori R, Yasue $\mathrm{H}$, Nakao K. Rapid ventricular induction of brain natriuretic peptide gene expression in experimental acute myocardial infarction. Circulation 1995;92(6):1558-64

42. Nazer B, Ray KK, Sloan S, Scirica B, Morrow DA, Cannon CP, Braunwald E. Prognostic utility of neopterin and risk of heart failure hospitalization after an acute coronary syndrome. Eur Heart J 2011;32(11):13907. doi:10.1093/eurheartj/ehr032

43. Ray KK, Morrow DA, Sabatine MS, Shui A, Rifai N, Cannon CP, Braunwald E. Long-term prognostic value of neopterin: a novel marker of monocyte activation in patients with acute coronary syndrome. Circulation 2007;115(24):3071-8.

44. Cruz-Gonzalez I, Pabón P, Rodríguez-Barbero A, Martín-Moreiras J Pericacho M, Sánchez PL, Ramirez V, Sánchez-Ledesma M, MartínHerrero F, Jiménez-Candil J, Maree AO, Sánchez-Rodríguez A, MartínLuengo C, López-Novoa JM. Identification of serum endoglin as a novel prognostic marker after acute myocardial infarction. J Cell Mol Med 2008;12(3):955-61. doi: 10.1111/j.1582-4934.2008.00156.x 
45. Knoflach M, Kiechl S, Mantovani A, Cuccovillo I, Bottazzi B, Xu Q Xiao Q, Gasperi A, Mayr A, Kehrer M, Willeit J, Wick G. Pentraxin-3 as a marker of advanced atherosclerosis results from the Bruneck, ARMY and ARFY Studies. PLoS One 2012;7(2):e31474. doi: 10.1371/ journal.pone.0031474
46. Latini R, Maggioni AP, Peri G, Gonzini L, Lucci D, Mocarelli P, Vago L, Pasqualini F, Signorini S, Soldateschi D, Tarli L, Schweiger C, Fresco C, Cecere R, Tognoni G, Mantovani A; Lipid Assessment Trial Italian Network (LATIN) Investigators. Prognostic significance of the long pentraxin PTX3 in acute myocardial infarction. Circulation 2004;110(16):2349-54. 